$(25) \mid(2)$

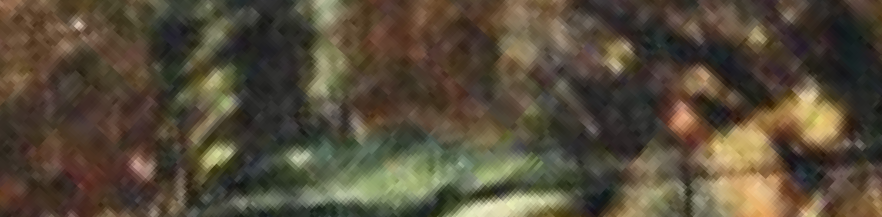

1

3.

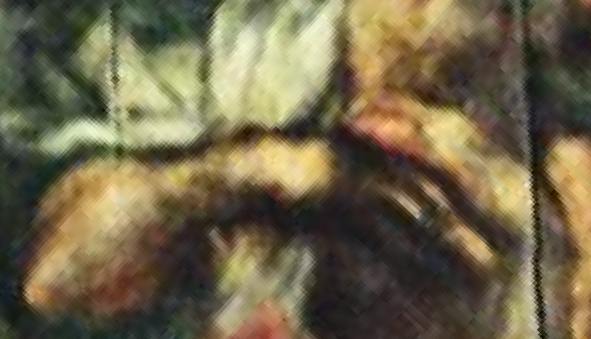
i.

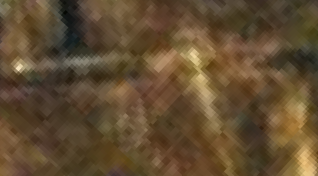
$x^{2}=$

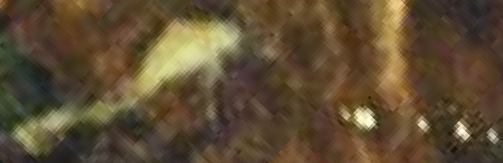

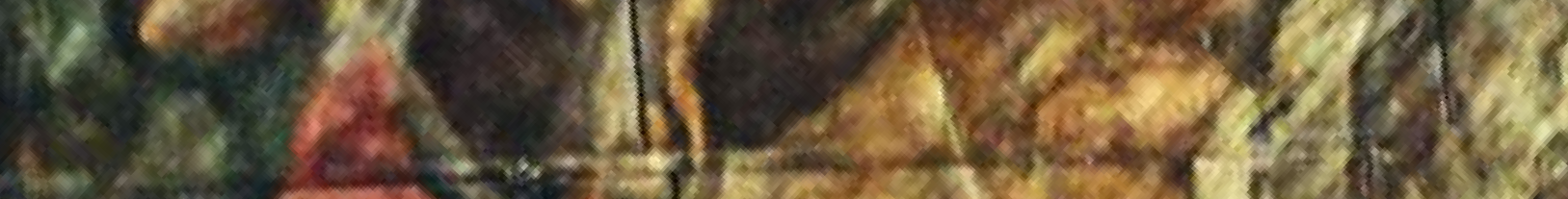
(3) 


\title{
Un pintor catalán en Lima virreinal: Félix Batlle y Olivella $(1796-1812)^{1}$
}

Anthony Holguín Valdez

Universidad Nacional Mayor de San Marcos anthony.holguin@unmsm.edu.pe

Lima-Perú

\begin{abstract}
Resumen
El presente artículo examina la biografía del pintor catalán Félix Batlle y Olivella en el contexto artístico limeño de finales del siglo XVIII y la primera década del XIX. Para este propósito, la investigación tiene como eje central el cotejo de fuentes primarias conservadas en archivos de Lima. Finalmente, analizaremos la única pintura conservada del artista; nos referimos a la Apoteosis de la Virgen Tota Pulchra del retablo mayor de la iglesia de San Pedro de Lima.
\end{abstract}

Palabras clave: Félix Batlle, pintura, siglos XVIII y XIX, iglesia San Pedro de Lima

\section{Abstract}

This article examines the Catalan painter Felix Batlle y Olivella's biography in Lima's artistic context at the end of the 18th century and the first decade of the 19th. For this purpose, the research has as its central axis the comparison of primary sources preserved in Lima archives. Finally, we will analyze the artist's only preserved painting; we refer to the Apotheosis of the Virgin Tota Pulchra of the San Pedro church main altarpiece in Lima.

Keywords: Felix Batlle, painting, XVIII and XIX centuries, San Pedro Church in Lima

La historia de la pintura virreinal limeña aún está por escribirse. Son escasas las investigaciones desde la disciplina de la historia del arte sobre este tema en particular y, en especial, sobre la presencia de pintores españoles en Lima, como es el caso del pintor catalán Félix Batlle. La primera noticia sobre el artífice la publica el fraile Víctor Barriga, en su obra sobre el templo mercedario de Lima, quien señala con referencias documentales que el pintor elaboró el dorado y pintura del altar mayor (Barriga, 1944). Años más tarde, el padre Vargas Ugarte cita la anterior referencia en su diccionario sobre artífices coloniales y agrega la noticia de la policromía del altar mayor de la iglesia San Pedro (Vargas Ugarte, 1947). Asimismo, Harth-Terré y Márquez adicionan la información biográfica del pintor sobre unos arreglos llevados a cabo en la Catedral de Lima, entre 1809 y 1810 (Harth-Terré y Márquez, 1963). En adelante, la atención sobre el pintor ha permanecido en silencio. Sin embargo, una reciente publicación del investigador Luis Wuffarden ha contextualizado la obra de Batlle dentro de los aportes de los oratorianos durante la reforma del altar mayor de la iglesia San Pedro de Lima a principios del XIX (Wuffarden, 2019).

1 La presente investigación no hubiera sido posible sin los permisos de las imágenes que acompañan este artículo. Por esto agradezco a José Enrique Rodríguez SJ, párroco de la iglesia San Pedro de Lima, y a Nancy Junchaya, encargada del taller de restauración de los bienes artísticos del templo. Un merecido reconocimiento al historiador del arte Li Cárdenas por brindarme un documento valioso que se empleó en la investigación. Finalmente agradezco a la historiadora del arte Tania Pérez por las conversaciones, lectura y sugerencias del presente estudio. 
100 En la presente investigación pretendemos ofrecer el itinerario del pintor Félix Batlle en el panorama histórico y artístico de Lima de finales del siglo XVIII y las primeras décadas del XIX, para luego analizar la única obra conservada del pintor, nos referimos a la pintura del ático del retablo mayor de la iglesia San Pedro de Lima. Para este objetivo, el trabajo está justificado en documentación primaria obtenida del Archivo General de la Nación (AGN), el Archivo Histórico de la Beneficencia Pública de Lima (AHBPL) y el Archivo Arzobispal de Lima (AAL).

\section{El taller de pintura en Lima de fines del siglo XVIII}

En 1786, en la ciudad de Barcelona (España), Félix Batlle otorgó su testamento ante el escribano público Josep Guerau Sayrols, ${ }^{2}$ siendo sus albaceas la esposa Teresa Batlle García y don Francisco García. El objetivo de la escritura pública coincide con el viaje del pintor a las Indias, puesto que redactar un testamento fue una costumbre muy extendida, sobre todo "cuando se tratase de un viaje por mar con los riesgos de naufragio, captura de piratas, etc." (Pieter, 2012, p. 86). Las circunstancias del viaje del pintor desvelan diversas interrogantes: ¿Qué lo motivó a emprender esta travesía? ¿Desde el principio el destino fue el virreinato peruano? ¿Viajó por negocios o comercio? ¿En Barcelona se dedicó exclusivamente a la pintura? Ciertamente es poco lo que conocemos de la actividad de Batlle en España y, por otra parte, la información de los años comprendidos desde su viaje y su asentamiento en América (1786 hasta 1795) son aún más inciertos.

La Lima de finales del siglo XVIII tuvo en los talleres de "maestros pintores" uno de los principales vehículos para la producción y circulación de pintura. Este grupo congregaba al maestro del taller, oficiales y aprendices. El mecanismo de difusión y enseñanza artística de los pintores se practicaba por medio del "asiento de aprendiz", escritura pública legalizada en un protocolo notarial. Se ingresaba al taller en calidad de aprendiz y el maestro brindaba la educación y manutención del aspirante (comida, vestimenta, atención médica y enseñanza de la doctrina cristiana). Durante un periodo de cuatro a cinco años, el aprendiz obtenía el grado de oficial y después de otro año solicitaba un examen profesional que le acredite como maestro.

El caso de los pintores de Lima y los asientos de aprendices es una práctica muy común en los protocolos notariales desde fines del siglo XVI; sin embargo, este tipo de escrituras decrecen considerablemente en la segunda mitad del XVIII, e incluso son menos frecuentes en las primeras décadas de la siguiente centuria.

La primera noticia de Félix Batlle en Lima es la escritura de un asiento de aprendiz firmada por el pintor (Fig. 1). El seis de abril de 1796, Batlle recibe como aprendiz al joven Sebastián Arriaga para enseñarle el oficio de "Arte de Pintor", por el periodo de cuatro años. La escritura señala lo siguiente:

Ante mi el escribano y testigos parecio Don Geronimo Arriaga a quien doy fee conozco y dijo que por quanto deseando que un hijo suyo nombrado Sebastian aprenda el Arte de Pintor lo paso con Don Felix Batlle Maestro de dicho Arte con tienda publica en la Plazuela de San Agustin para que en el tiempo de quatro años le enseñe perfectamente obligándose a darle de almorzar, comer y cenar, ropa limpia cada ocho días y un real en los festivos junto con dos horas de hueco para que se paseé igualmente le enseñara la Doctrina Christiana y curara ocho días caso que este enfermo en su casa y pasados lo llevara al Hospital que le corresponda. ${ }^{3}$

La escritura pública es útil como fuente indirecta, puesto que indica la tienda del pintor ubicada en la plazuela de San Agustín. Sabemos que otros artistas extranjeros trabajaron

2 AGN, escribano Manuel Udias, protocolo 963, f. 92r; Manuale instrumentorum, AHOB, 1.114/13 (Cases I Loscos, 2009, p. 237).

3 AGN, escribano Juan Castañeda, protocolo 184,7 de mayo, f. $148 v$ y 149 r. 


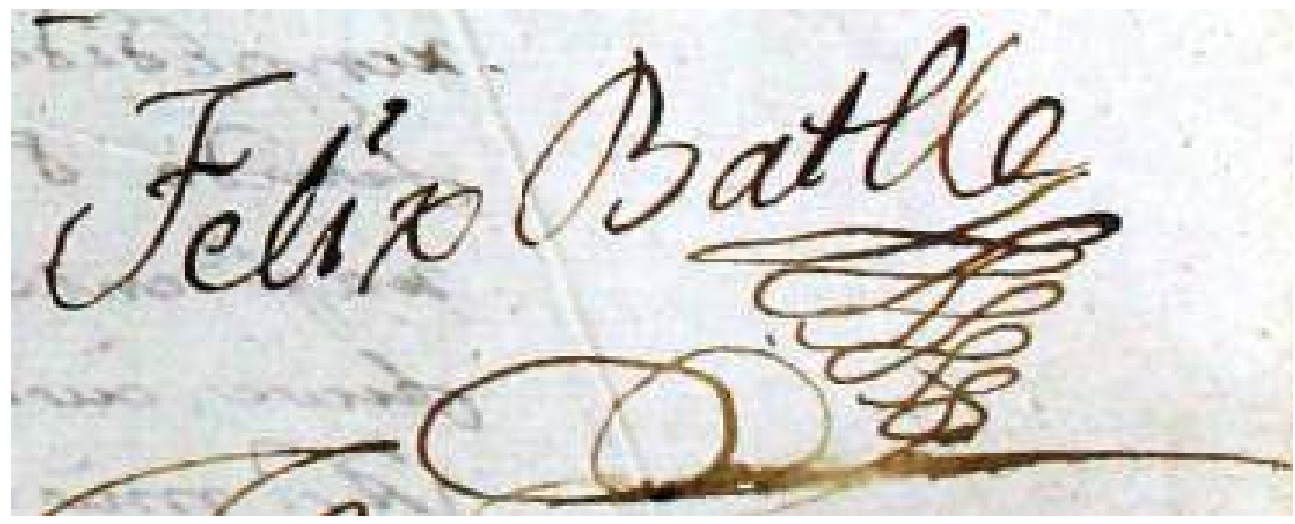

Fig. 1. Félix Batlle. Rúbrica de asiento de aprendiz. Tinta sobre papel verjurado. Fuente: Archivo General de la Nación.

en la citada calle, como fueron los casos de Silvestre Jacobelli ${ }^{4}(1799)$ y José del Pozo (1801). ${ }^{5}$

Ahora bien, la actividad artística estuvo vinculada a los talleres "artesanales" y su acepción "mecánica" obligaba a que los maestros pintores se autodefinieran con los títulos de "Maestro en el Arte de la Pintura"6 o "Maestros Inteligentes del Arte de la Pintura", esto con el objetivo de liberalizar el oficio, además, esta práctica presenta sus antecedentes desde el siglo XVII. Por otra parte, la Real Cédula española del primero de mayo de 1785 permitía la práctica libre de "la profesión de las nobles artes del dibujo, pintura, escultura, y arquitectura” (Coronas, 2003, p. 3052), y acogerse a ejercitarla sin "estorbo ni contribución alguna”, pero en la práctica limeña se percibió confusa. En efecto, los pintores persistieron en establecer un gremio para proteger sus privilegios, y sabemos que su último intento fue conformar una ordenanza ante el Cabildo de Lima en 1797 (Holguín, 2019, p. 79), hecho que no se llegó a concretar.

Entonces, los asientos de aprendiz no fue una práctica generalizada entre los pintores de fines del XVIII. Son pocos los artífices que legitiman la actividad en los protocolos, por ejemplo, sabemos los casos de los pintores Julián Jayo y Pedro Díaz. Ambos artífices reciben aprendices de la Real Casa de Niños expósitos de Nuestra Señora de Atocha, institución que tuvo el cuidado de los niños huérfanos de la ciudad de Lima. Así pues, en una escritura fechada el 16 de mayo de 1781, el mayordomo y administrador de la casa de expósitos, don Thomas Arandilla y Sotil, acordaba con Julián Jayo entregarle a Mathias de Atocha, "huérfano español", para enseñarle el "Arte de Pintor". ${ }^{8}$ Mientras tanto, Pedro Díaz presenta tres escrituras de aprendices. El primero se sitúa en agosto

4 En su testamento declara ser habitante de la calle de Plateros de San Agustín. AGN, escribano José de Cárdenas, protocolo 177, f.135v.

5 En 1801, José del Pozo alquilaba una vivienda en la calle de Plateros de San Agustín. AGN, CA-JO 1, legajo 143, expediente 2564, f.1r.

6 En 1788, el pintor Manuel Paz se declaraba con este título en una tasación de pintura. AGN, Superior Gobierno, legajo 19, expediente 519, 14-03-1788, f. 6v

7 El autodenominarse o ser reconocido con este título significaba la dignidad de su oficio; inclusive en las tasaciones que los pintores realizan a colecciones pictóricas en la primera mitad del siglo XVIII podemos encontrar el título de "Maestros Inteligentes del Arte de la Pintura", sin duda, una manera mediante la cual el artífice declaraba dicha dignidad ante la autoridad, en este caso, el coleccionista aristocrático. Ejemplos de estas presentaciones los encontramos en la tasación que realiza Cristóbal Lozano y Lorenzo Ferrer en la pinacoteca de María de los Olivos, en 1738. AGN, escribano Pedro de Espino Alvarado, protocolo n. ${ }^{\circ} 296$, 1738 , fs. 54-58v.

8 AGN, escribano Alejandro Cueto, protocolo 201, f. 80v-81v. 
de 1779 , cuando se registra a Josef de Atocha, "huérfano español", ${ }^{9}$ y los dos restantes asientos firmados en 1783 presentan a José Velasco ${ }^{10}$ y José Patrocinio. ${ }^{11}$ La nómina de los huérfanos inscritos en distintos talleres se multiplica entre los años de 1779 hasta 1789 , siendo el de platero el principal rubro. ${ }^{12}$ Fuera del ámbito de los talleres, la escuela de dibujo fundada por José del Pozo en 1791, fue una pequeña institución de formación artística desde la mirada de la ilustración, siendo el caso de Antonia Herencia el único nombre de los discípulos del pintor sevillano (Holguín, 2019).

\section{Itinerario profesional de Félix Batlle}

El pintor nace en el pueblo de Sant Cristófol de Beget, ubicado en la provincia de Gerona, Cataluña (España), y sus padres fueron José Batlle y María Batlle y Olibella. ${ }^{13}$ La primera obra que Félix Batlle realiza en Lima fue el encargo de la congregación de Nuestra Señora de la O. Esta corporación convocó al pintor y a José Mendoza para elaborar la pintura y dorado de su nuevo retablo en la iglesia San Pedro, ambos maestros pintores "lo decoraron con jaspe 'blanco al óleo', dorado de molduras y la decoración de las columnas en verde con blanco por 2,800 pesos" (Gonzales, 2018, p. 61). La especialización de Batlle en la pintura de altares está documentada en diversas ocasiones. En efecto, en 1799, la archicofradía de la Virgen del Rosario de los Españoles, ubicada en la iglesia Santo Domingo, encargó al catalán remodelar al "buen gusto" la pintura del retablo mariano. El libro de cuentas anota los detalles de las refacciones que tuvo que realizar en el retablo:

Pesos pagados al Catalan D. Felix Batlle, quatrocientos valor de la Pintura de colores, jaspes echos en el Retablo, encargado, y esmaltado, quatro Ymagenes que representan los misterios de la Encarnacion, y visitación, y por el dorado en el respaldar del santo Christo, trono de N.S. El escudo grande del Maria y trescientos por razón de las piezas de plata que doro a fuego; advirtiéndose que aunque este dorado no es oro fino, pero es mui semejante, y de la misma vista, y duración que aquel. ${ }^{14}$

Las labores de Batlle en el retablo de la Virgen del Rosario consistían en los "embellecimientos" que la archicofradía realizaba cada año del aniversario y celebración de la advocación mariana. El recibo del pintor nos da a conocer que conocía técnicas artísticas propias de los maestros plateros, como el dominio del "dorado a fuego". ${ }^{15}$ Sabemos, además, que las labores de pintura anteriores a Batlle las realizaba Julián Jayo. ${ }^{16}$ Asimismo, durante las actividades del pintor catalán, Francisco Xavier Aguilar elaboró la pintura del ciclo biográfico de la Virgen María en el camarín del retablo. ${ }^{17}$ Décadas más tarde no hay presencia de Batlle en los trabajos del nuevo retablo de la archicofradía bajo la supervisión de Matías Maestro.

9 AGN, escribano Alejandro Cueto, protocolo 202, f. 247r.

10 AGN, escribano Alejandro Cueto, protocolo 201, f. 190 y 190v.

11 AGN, escribano Alejandro Cueto, protocolo 201, f. 190v-191v.

12 El 22 de octubre de 1779, Nicolás de Atocha se asienta como aprendiz del maestro platero de oro, don Pedro Vidal (f. 379r y 379v). El 20 de abril 1781, Toribio de Atocha es recibido en el taller del maestro platero Mariano Palomino (f. 55r y 55v). El 11 de mayo Pablo de Atocha ingresa al taller del maestro platero de oro, don Esteban de Luza (f. 79r). El 3 de octubre de 1783, Miguel de Atocha ingresa al taller del maestro platero de oro José Guevara (f. 295v). AGN escribano Alejandro Cueto, protocolo 201.

13 AGN, escribano Manuel Udias, protocolo 963, f. 91v y 92r.

14 AHBPL, signatura PE_0006_AHBPL_COF_ROS_029, Libro de cuentas de la Cofradía de Españoles Nuestra Señora del Rosario (Convento Santo Domingōo), fs. $\overline{4} 75, \overline{4} 92,495$.

15 Proceso de amalgamiento del oro con el mercurio sobre la pieza de plata.

16 Jayo elaboró las pinturas de las barandas del altar y el presbiterio. El primero está documentado en octubre de 1791; el segundo en octubre de 1793. AHBPL, signatura PE_0006_AHBPL_COF_ROS_029, Libro de cuentas de la Cofradía de Españoles Nuestra Señora del Rosario (Conventō Santo Domingo), f. 66 y 233.

17 AHBPL, signatura PE_0006_AHBPL_COF_ROS_030, Libro de cuentas de la Cofradía de Españoles Nuestra Señora del Rosario (Convento Santo $\bar{D}$ omingo $\overline{\text { ) }}$, f. $\overline{87}$ y $1 \overline{1} 7$. 


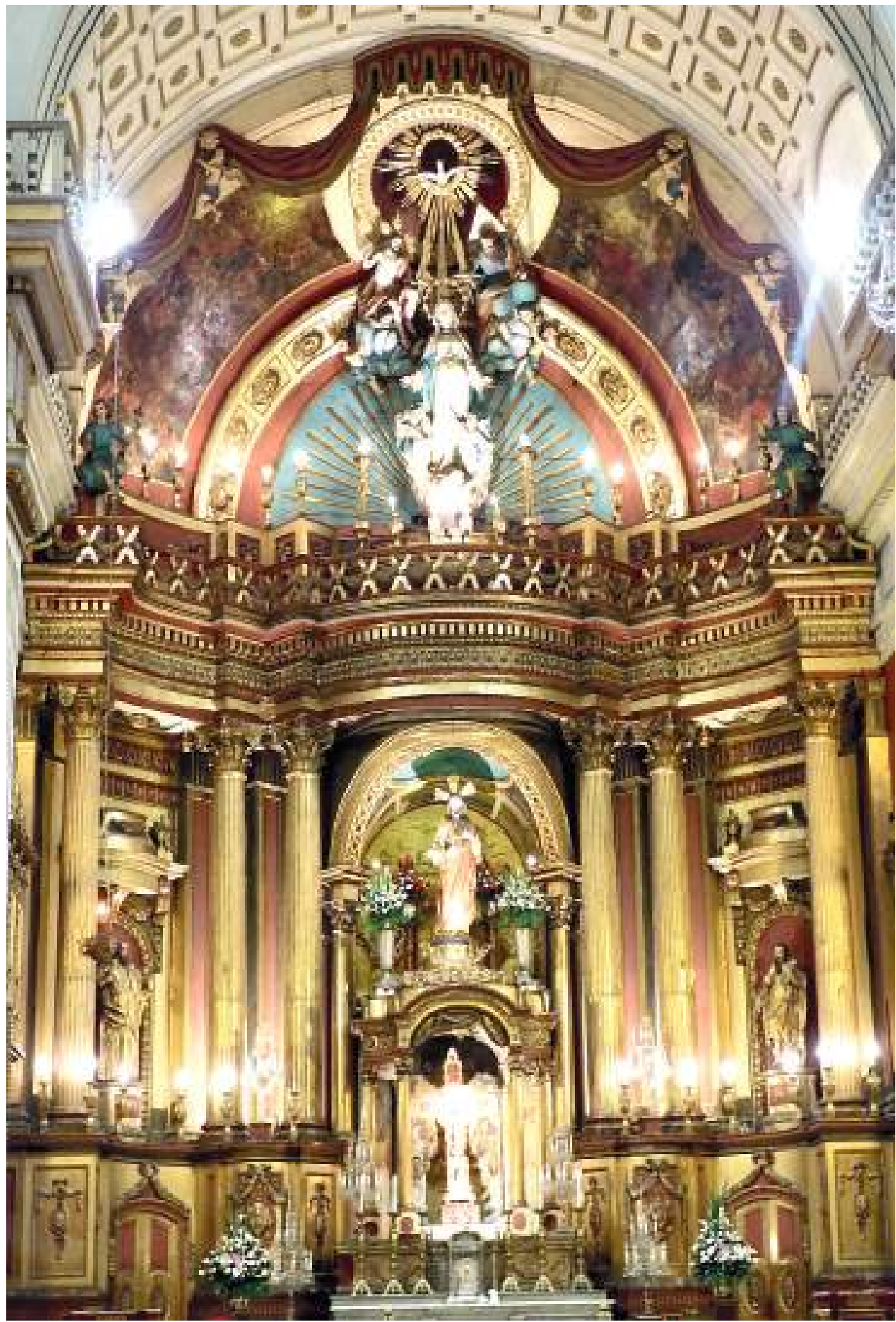

Fig. 2. Matías Maestro, Juan Pablo Mesías y Félix Batlle. Altar Mayor de la Trinidad y la Virgen Tota Pulchra. Madera talla, dorada y policromada, 1809. Iglesia de San Pedro de Lima. Fotografía: Anthony Holguín. 


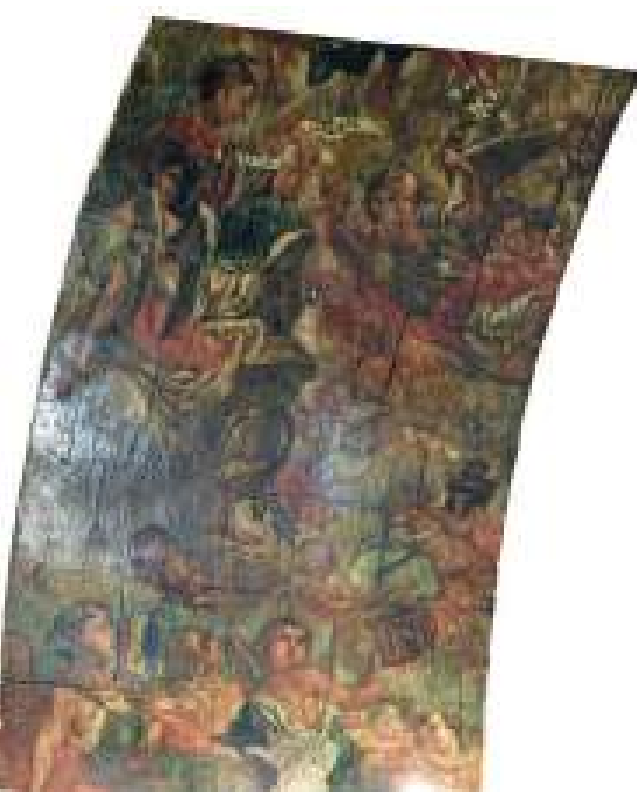

Fig. 3. Félix Batlle y taller. Apoteosis de la Virgen Tota Pulchra (detalle). Óleo sobre lienzo, sin medidas disponibles, 1809. Iglesia de San Pedro de Lima. Fotografía: Anthony Holguín.

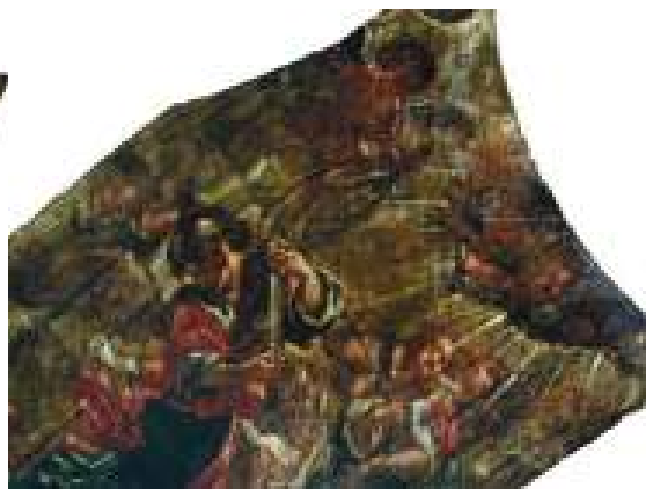

Fig. 4. Félix Batlle y taller. Apoteosis de la Virgen Tota Pulchra (detalle). Óleo sobre lienzo, sin medidas disponibles, 1809. Iglesia de San Pedro de Lima. Fotografía: Anthony Holguín.

En 1802, Félix Batlle entabla un juicio a don Manuel del Solar, cobrador de la cofradía de Jesús Nazareno, ${ }^{18}$ fundada en la iglesia dominica de Lima. El motivo de esta disputa fue el pago de los asientos de hermanos en la corporación religiosa, aunque no se indica que el pintor formara parte de la cofradía; los lazos de Batlle

con miembros vinculados a comunidades religiosas fue una herramienta de ascenso profesional. Un año después, Batlle legaliza su testamento, siendo sus albaceas don José Ysari y su hijo Manuel Batlle; este último, según se informa en la escritura, se declara que residía junto al pintor. ${ }^{19}$ El pintor señala estar "en pie, y en sana salud", por lo que las razones de escribir su testamento deben situarse en un posible viaje de negocios. En esta misma escritura el pintor estipula, en caso de que falleciera, entregar 300 pesos a su hijo Miguel para sus gastos de viaje a Barcelona. La cláusula se cancela el 12 de octubre de 1811 , en donde Batlle declara como nuevos albaceas y tenedores de bienes a José Gus y al citado José Ysari. ${ }^{20}$

Unos meses antes de la renovación de cláusula testamentaria, Félix Batlle demanda al capitán don Ignacio de Alcasar y al maestro enjoyador José Beltrán, por la deuda de 4800 pesos de la venta de "diez negros bozales". ${ }^{21}$ El comercio de esclavos en el virreinato tuvo un reinicio con más fuerza a fines del XVIII. Así, entre 1790 y 1802 probablemente ingresaron más de 65 000, y en 1812 había en el Perú 89241 esclavos (Hünefeldt, 1979). Este comercio no fue ajeno a pintores de cierta solvencia económica para incursionar en este rubro, por ejemplo, en enero de 1795, el pintor Pedro Díaz compra un "negro nombrado Manuel” de propiedad de Bartolomé de las Heras, entonces obispo del Cuzco. ${ }^{22}$ Sin embargo, el negocio emprendido por Batlle se relaciona con la creación de redes de comercio con posibles

18 AGN, Real Audiencia-Juzgado de cofradías, legajo 15, expediente 377, fs. 1-8.

19 AGN, escribano Manuel Udias, protocolo 963, f. 92r. Sobre la cofradía de Jesús de Nazareno, la noticia más temprana de su existencia es en 1660, un auto seguido por el bachiller Luis de Herrera, promotor fiscal del arzobispado, contra José Molero, mayordomo de la cofradía de Jesús de Nazareno (convento de Santo Domingo), para que le paguen una cantidad de pesos por la cera que les ha proveído. AAL, serie de cofradías, legajo 31, expediente 19, fs.1-5.

20 AGN, escribano Manuel Udias, protocolo 963, f. 91v y 92r [nota marginal].

21 AGN, Real Audiencia-Causas Civiles, legajo 109, expediente 1156, f. 1 r.

22 AGN, escribano Pedro Lumbreras, protocolo 587, fs. 330r y 330v. 
lazos externos a la ciudad, y esto se advierte en un expediente judicial, en el cual se indica que "don Félix tenga [que] salir de esta ciudad [de Lima] en algún buque para Buenos Ayres ú otro qualquier puerto". ${ }^{23}$ En efecto, el expediente demuestra que Batlle y sus clientes culminaron en noviembre de 1812, cuando el pintor recibe como pago "un sortija de un solo diamante grande". ${ }^{24}$ En adelante no hemos ubicado en los archivos la presencia del pintor en algún proyecto artístico u otro negocio comercial.

\section{Apoteosis de la Virgen Tota Pulchra del retablo mayor de la iglesia de San Pedro de Lima}

La Congregación del Oratorio de San Felipe Neri, corporación dedicada a la educación de las primeras letras para los desprotegidos y la atención espiritual, ocupó el templo de San Pedro de Lima, luego que la Compañía de Jesús fuera expulsada en 1767. A inicios del XIX, los oratorianos decidieron "perfeccionar" el altar mayor del templo e integrar parte de la reforma clasicista llevada a cabo por el Cabildo Catedralicio de Lima, cuyo principal impulsor fue el presbítero vasco Matías Maestro ${ }^{25}$. Justamente, la colaboración de Félix Batlle en las reformas emprendidas por Maestro está registrada en tres ocasiones: primero, el dorado y pintura del Altar Mayor de la Iglesia de la Merced (Barriga, 1944, p. 378); segundo, el pintor tuvo a su cargo los "arreglos llevados a cabo en la Catedral de Lima en los años de 1809 y 1810" (HarthTerré y Márquez, 1963, p. 71); y, por último, el retablo mayor de la iglesia San Pedro.

La obra del nuevo retablo se inició a mediados de 1807 , bajo la dirección del presbítero Matías Maestro, quien

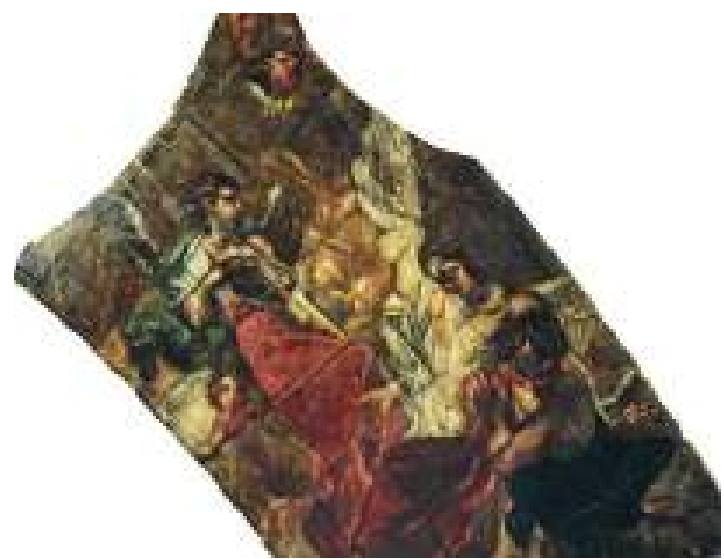

Fig. 5. Félix Batlle y taller. Apoteosis de la Virgen Tota Pulchra (detalle). Óleo sobre lienzo, sin medidas disponibles, 1809. Iglesia de San Pedro de Lima. Fotografía: Anthony Holguín.

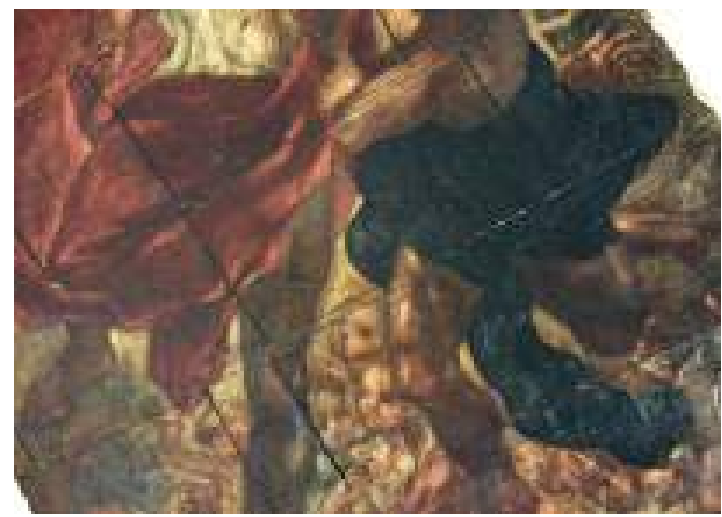

Fig. 6. Félix Batlle y taller. Apoteosis de la Virgen Tota Pulchra (detalle). Óleo sobre lienzo, sin medidas disponibles, 1809. Iglesia de San Pedro de Lima. Fotografía: Anthony Holguín.

elaboró el diseño, mientras que la ensambladura y carpintería estuvieron a cargo del retablista Juan Pablo Mesías ${ }^{26}$ (Fig. 2). Esta obra sigue una traza arquitectónica que transita un

23 AGN, Real Audiencia-Causas Civiles, legajo 109, expediente 1156, f. 1v.

24 AGN, Real Audiencia-Causas Civiles, legajo 109, expediente 1156, f. 28r-30r.

25 Desde mediados del siglo XIX se conoce la extensa labor de caridad emprendida por Matías Maestro, así como su "mérito artístico" en la renovación de muchos templos limeños y proyectos arquitectónicos en instituciones civiles. Se decía que fueron algunas de sus principales obras "la iglesia de San Lázaro y sus torres, el altar mayor de Trinitarias, los de Santo Domingo, San Francisco, Soledad, Sagrario y Mercedarias; los cuadros que hermoseaban la antigua capilla del Milagro (...)", agréguese el tratado de arquitectura que compuso con el título Orden Sacro (Sociedad de Beneficencia de Lima, 1857, p. 19). Para un panorama general de la biografía y obra de Matías Maestro, véase González de Zárate (2007).

26 AAL, Oratorio de San Felipe Neri, legajo 1, expediente 41, f. 41r. 

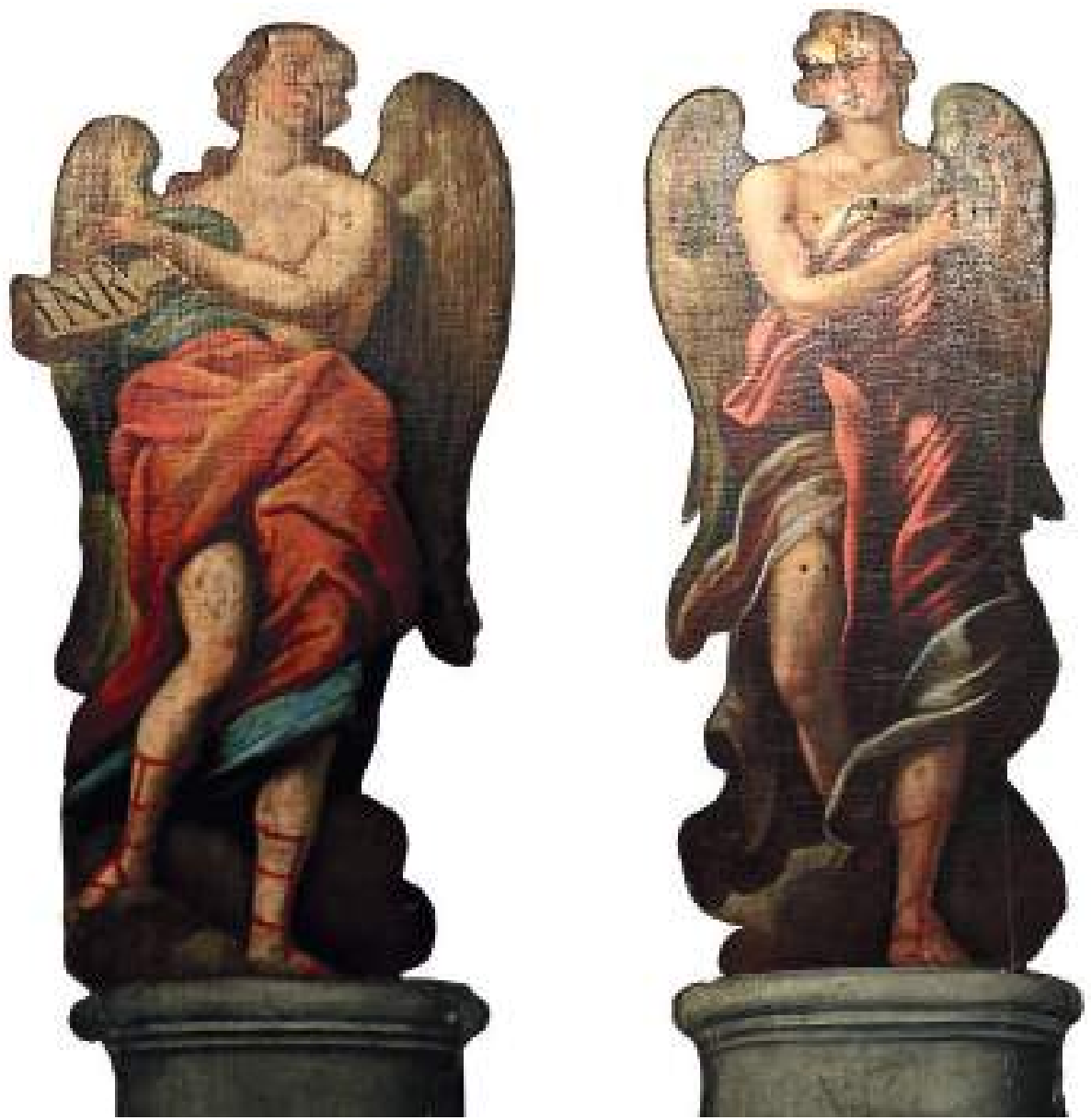

Fig. 7. Félix Batlle (atribuido). Ángeles. Óleo sobre lienzo, c. 1810. Catedral de Lima. Fotografía: Anthony Holguín.

método y tradición italiana de formas procedentes del barroco romano, que está compuesto de un cuerpo central de forma curva convexa y de alas cóncavas que lo flanquean y se proyectan hacia adelante; en lugar de un segundo cuerpo, el retablo posee una coronación a manera de tímpano o media luna que sigue el trazo de la bóveda. A su vez, está conformada por paneles curvos con la representación pictórica del coro celestial de la Tota Pulchra. ${ }^{27}$ Cierra la composición un "transparente" 28 suspendido en un palio que sirve de culminación a una representación escultórica de la Santísima Trinidad con la Virgen Inmaculada (García Bryce, 1972, p. 53). Matías Maestro ha elaborado este proyecto según el diseño del arquitecto español Ventura Rodríguez para el altar de la parroquia de San José de Granada (España, 1789); sin embargo, el vasco expande el cuerpo del retablo limeño y agrega columnas en cada calle. Asimismo, elimina los recuadros del arco para dinamizar el ilusionismo barroco de la pintura de Félix Batlle. El 21 de mayo de 1808, don José de Castro, presbítero del Oratorio de San

27 Antes de que se configurara definitivamente la iconografía de la Inmaculada Concepción, apareció un tipo intermedio, cuyo título procede de las primeras palabras del versículo 7 del capítulo 4 del Cantar de los Cantares: Tota pulchra es, amica mea, et macula non est in te (Eres toda hermosa, amiga mía y no hay mancilla en ti) (Schenone, 2008, p.28).

28 La función del "transparente" en los retablos permite realizar juegos de luz atendiendo a la simbología de la liturgia. Bonet, 2001, p. 641. 
Felipe Neri, otorga a Félix Batlle el presupuesto de las obras de pintura y dorado del nuevo retablo mayor. Por todo el trabajo el pintor recibió cinco mil pesos, un precio estimado por debajo de lo que cobró en el altar mayor de la Merced, en donde "se le dieron a Don Felix Batlle para materiales, oficiales y su arreglo siete mil pesos" (Barriga, 1944, p. 378). En junio del mismo año, el pintor firma la obligación de culminar las obras según "el decoro debido", de modo que el retablo se debió estrenar el ocho de diciembre, día celebratorio de la Purísima Concepción de María ${ }^{29}$. Sin embargo, la obra se culminó en febrero de 1809, y Batlle declara haber "concluido el Altar a la posible perfección", según el contrato estipulado por el oratorio. ${ }^{30}$ La pintura y dorado de Félix Batlle se acordó en veintiún cláusulas. El primer artículo del contrato nos interesa, pues atañe a la obra de Apoteosis de la Virgen Tota Pulchra, pintura vinculada al género del trampantojo del ilusionismo barroco. La razón estipula que "primeramente [debe] pintar el arco que toca con la bóveda que al presente se halla una griega (sic) de color y barnis al gusto del L[icenciado] D[on] José de Castro"; ${ }^{31}$ en efecto, observamos que el presbítero impone las reglas del decoro de una nueva pintura del arco, ${ }^{32}$ atendiendo la dirección de Matías Maestro, según se desprende del contrato de Batlle. ${ }^{33}$ Lamentablemente, el documento no detalla la escena iconográfica del arco; no obstante, en la cláusula octava se indica que el sagrario se pintó y doró “enteramente por dentro con el cielo de gloria” y que en la actualidad ha recibido considerables repintes. En tanto, la crítica ha calificado de "pintura de calidad mediocre" la obra del arco y del sagrario. Desde nuestra perspectiva creemos que la obra del ático que titulamos con el nombre Apoteosis de la Virgen Tota Pulchra merece un análisis más riguroso, por enmarcarse dentro de la estética implantada por el presbítero Matías Maestro.

La advocación titular de retablo ${ }^{34}$ oratoriano en el siglo XIX se manifestó en la imagen de la Santísima Trinidad y de la Virgen Tota Pulchra, y los dos paneles de pinturas en forma de arco que acompañan la composición refuerzan la escenografía de la apoteosis mariana. Félix Batlle emplea el término "pintura de color" para referirse a la pintura al óleo ${ }^{35}$ del arco y esta presenta un acabado de barniz, ${ }^{36}$ todo el conjunto está ensamblado por

29 AGN, escribano Ignacio Ayllon Salazar, protocolo 10, fs. 555-556. Agradezco al historiador del arte Li Cárdenas por proporcionarme este documento.

30 Se concluyó la pintura y dorado del retablo mayor, a excepción del frontal, por lo cual el pintor solicitó un nuevo presupuesto. Con este fin, Batlle nombra al pintor Julián Jayo "Maestro de notoria inteligencia en el Arte" para evaluar dicho frontal. AAL, Oratorio de San Felipe Neri, legajo 1, expediente 41, f. 13v.

31 AGN, escribano Ignacio Ayllon Salazar, protocolo 10, f. 557; AAL, Oratorio de San Felipe Neri, legajo 1, expediente 41 , f. 8 r.

32 La cláusula indica que Batlle debe obrar una nueva pintura sobre una "griega (sic) de color y barnis", es decir, una greca o cenefa, por lo general eran diseños polícromos de pequeños vegetales y figuras geométricas entrelazadas.

33 Matías Maestro elaboró un segundo retablo con pintura apoteósica sobre el ático, en este caso fue en la iglesia del Sagrario de Lima, y la obra estuvo a cargo de José del Pozo, cobrando un total de 1767 pesos (Holguín, 2019, p. 102).

34 La preferencia de los oratorianos por estas advocaciones reside en el hecho de que Felipe Neri estableció en 1548 la congregación con el nombre de la Santísima Trinidad; en segundo lugar, la devoción de San Felipe en la imagen de María reside en una de sus invocaciones favoritas que fue "Virgen Maria, Madre de Dios, rogad á Jesús por mí” (J.M.N, 1854, p. 33 y 126). Por otra parte, desde sus primeros años de fundación, la Compañía de Jesús tuvo como santos titulares de su altar mayor a San Pablo y San Pedro y en el nicho principal se rendía culto, desde antiguo, a una devota imagen de la Santísima Virgen, bajo la advocación de los Remedios (Vargas Ugarte, 1963, p. 35; Solari, 1982, p.86; Wuffarden, 1996, p. 50). Según el historiador Ramón Mujica, en 1638 la iglesia San Pedro inauguró el retablo mayor donde estuvo ubicado el lienzo de la Asunción de la Virgen pintado por Bernardo Bitti. Este altar permanecería hasta la remodelación llevada a cabo por Matías Maestro (Mujica, 2019, p. 154).

35 El pintor Félix Batlle emplea la pintura al óleo en la obra de "encarnes" de esculturas y "jaspeados" de columnas. AHBPL, signatura PE_0006_AHBPL_COF_ROS_029, Libro de cuentas de la Cofradía de Españoles Nuestra Señora del Rosario (Convento Sañto Domingo), $\overline{\mathrm{f}} .49 \overline{\mathrm{r}}$.

36 El estado de conservación de la pintura limita a un análisis con más detenimiento por el ennegrecimiento del barniz. 


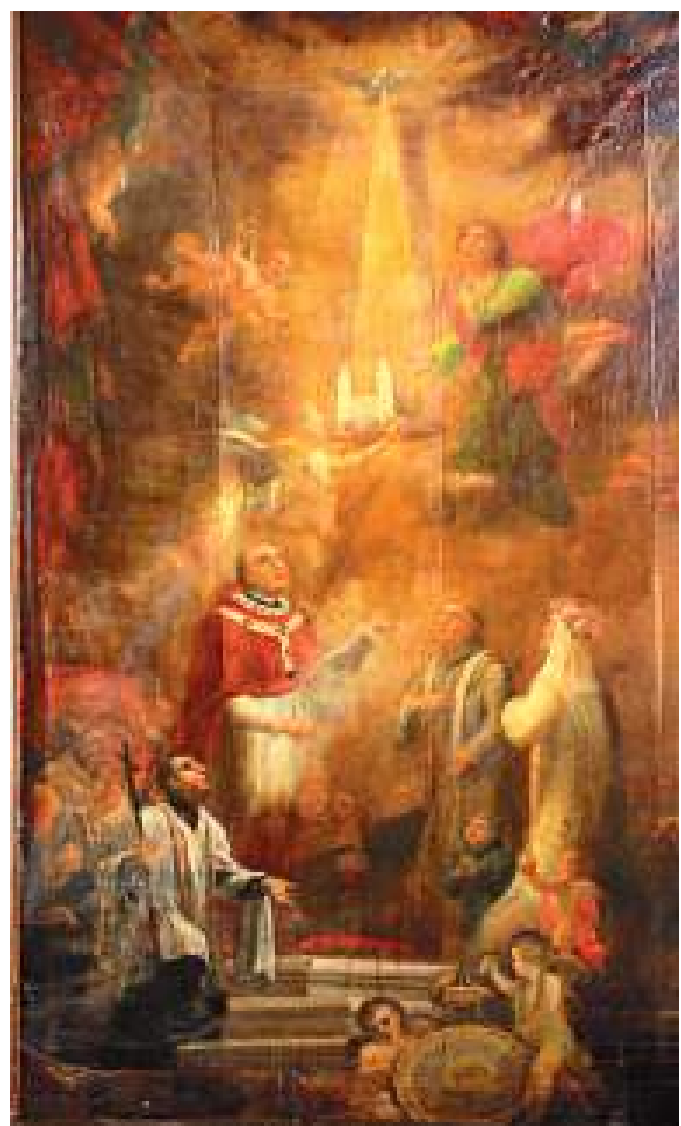

Fig. 8. Círculo de Matías Maestro. Apoteosis de la iglesia de San Juan Evangelista. Óleo sobre lienzo, sin medidas disponibles, c. 1085 Catedral de Lima. Fotografía: Anthony Holguín. paneles cuadrangulares que se prolonga según la traza cóncava de las calles laterales del retablo; de esta manera pueden situarse las líneas de perspectiva que se proyectan en la imagen de María como punto de fuga. La escena del arco izquierdo (Figs. 3 y 4) representa un coro de ángeles y querubines volantes, uno de ellos abraza el Libro de los Cantares y otro extiende con las manos una filacteria con la inscripción TOTA PULCHRA ET MARIA; se suman al acontecimiento otros ángeles portando algunos de los símbolos lauretanos de la Tota Pulchra: Espejo, ${ }^{37}$ Templo, ${ }^{38}$ Torre de David ${ }^{39}$ y el Lirio. ${ }^{40}$ El arco derecho incorpora un grupo de ángeles monumentales que elevan el envés rojo del manto de la Inmaculada ${ }^{41}$ (Figs. 5 y 6), se insinúa el empleo del escorzo, además, sugerimos que el modelado de los seres alados en los drapeados de las telas y de los cuerpos esbeltos y alargados se identifica con el estilo de dos ángeles contemporáneos que hoy se conservan en la Catedral de Lima (Fig. 7).

Predominan en la pintura los colores cálidos, como el rojo y ocre de su paleta, contrarrestando con el blanco de los drapeados de los mantos, y el uso de contrastes de luces y sombras crea una escena acorde al estilo del barroco sevi-

llano de la segunda mitad del seiscientos: composición asimétrica; un complejo dinamismo estructural; una paleta de color contrastada de tonos cálidos; un artificioso juego lumínico con zonas en penumbra y otras insoladas; una pincelada dinámica y vibrante (García, 2019, p. 476). Este último punto -la pincelada que identificamos en Félix Batlle- se articula en la ejecución de delicados sfumatos, en donde la línea no es predominante y genera una atmósfera de continuo movimiento. En efecto, esta técnica fue la preferida en los proyectos pictóricos que llevó en marcha Matías Maestro durante las primeras décadas del XIX, así, por ejemplo, la composición del lienzo Apoteosis de la iglesia de San Juan Evangelista (Fig. 8) demuestra claramente los referentes formales de la pintura escenográfica y efectista del barroco tardío.

37 Un espejo sin mancha de la actividad de Dios.

38 Templo de Dios.

39 Tu cuello es como la Torre de David.

40 Como un lirio entre espinas.

41 Hasta la primera mitad del siglo XVII, la túnica roja fue empleada por los pintores del barroco español; sin embargo, luego se remplazó por la túnica blanca, porque los tratadistas inmaculistas consideraban que esta fue la imagen con la que se presentó a Beatriz de Silva, la fundadora de la orden concepcionista. Los preceptos del color del manto no estuvieron estrictamente controlados en la pintura virreinal peruana. En ocasiones, particularmente en la imaginería del siglo XVIII, el envés está pintado de color rojo (Schenone, 2008, p. 45). 


\section{Referencias bibliográficas}

Barriga, V. (1944). El templo de la Merced de Lima. Documentos para la Historia del Arte. Arequipa: Establecimientos Gráficos La Colmena, S. A.

Bonet, M. (2001). El retablo barroco, escenografía e imagen. En F. Campos y Fernández (Coord.). El Monasterio del Escorial y la pintura: actas del Simposium, 1/5-IX-2001. Madrid: Instituto Escurialense de Investigaciones Históricas y Artísticas, pp. 623-642.

Cases, L. (2009). Inventari de L'arxiu Históric de Protocols de Barcelona. 6. Segle XVIII. 17511800. Barcelona: Fundació Noguera.

Coronas, S. (2003). El libro de las leyes del siglo XVIII. Tomo quinto. Libros XIII a XVIII (1782-1787). Madrid: Boletín Oficial del Estado y Centro de Estudios Políticos y Constitucionales.

García Bryce, J. (1972). Del Barroco al Neoclasicismo en Lima: Matías Maestro. Mercurio Peruano, n. ${ }^{\circ} 480$, pp. 48-68.

García, A. (2019). Murillo, Valdés Leal, Herrera el Mozo y la llegada del Pleno Barroco. En Benito Navarrete (coord.). Murillo ante su IV Centenario. Perspectivas historiográficas y culturales. Sevilla: Editorial Universidad de Sevilla, pp. 471-482.

González de Zárate, J. (2007): Matías José Maestro (1766-1835), arquitecto, escultor, pintor, músico, escritor. Vitoria: Diputación Foral de Álava, Departamento de Euskera, Cultura y Deportes.

Gonzales, J. (2018). Nuestra Señora de la O. Congregación de seglares en San Pedro de Lima. Lima: Compañía de Jesús. Comunidad de San Pedro.

Harth-Terré, E. y Márquez, A. (1963). Pinturas y pintores en Lima virreinal. Lima: Librería e Imprenta Gil, S.A.

Holguín, A. (2019). Los lienzos de San Diego de Alcalá de José María del Pozo y Téxada. El último pincel del barroco sevillano en el epílogo virreinal. [tesis para optar el título de Licenciado de Arte]. Escuela Profesional de Arte, Facultad de Letras y Ciencias Humanas, Universidad Nacional Mayor de San Marcos, Lima, Perú.

Hünefeldt, C. (1979). Los negros de Lima: 1800-1830. Histórica, 1 (3), pp. 17-51.
J.M.N. (1854). Vida de San Felipe Neri, fundador de la Congregación del Oratorio en Roma; traducida al francés del latín de los bolandistas, por el abate P. Orizaba: Imprenta de J. M. Naredo.

Mujica, R. (2019). Retablos y devociones para el "Salomón de las Indias". De la máquina barroca al teatro de la memoria. En Ramón Mujica, Luis Wuffarden y Juan Dejo (Coords.). San Pedro de Lima. Iglesia del Antiguo Colegio Máximo de San Pablo. Lima: Banco de Crédito del Perú, pp. 141-203.

Pieter, A. (2012). Los movimientos migratorios entre España y el Nuevo Mundo en los archivos de protocolos españoles y latinoamericanos. Temas Americanistas, 29, pp. 82-92.

Schenone, H. (2008). Santa María: iconografía del arte colonial. Buenos Aires: Educa.

Sociedad de Beneficencia de Lima (1857). Traslación a dos mausoleos de los restos de los finados señores doctor don Matías Maestro y don Antonio chacon. Lima: Imprenta del "Católico”, por José Daniel Hureta.

Solari, M. (1982). Orgullos del Perú. San Pedro de Lima, la penitenciaria y la Virgen de la 0. Lima: Peruinvest, Compañía de Fomento e Inversiones S.A.

Vargas Ugarte, R. (1947). Ensayos de un diccionario de artífices coloniales de la América Meridional. Buenos Aires: Talleres Gráficos A. Baiocco y Cía, S.R.L.

Vargas Ugarte, R. (1963). Los jesuitas del Perú y el arte. Lima: Imprenta Gil.

Wuffarden, L. (1996). Retablos e imágenes en San Pedro de Lima. En Fondo Pro Recuperación del Patrimonio Cultural de la Nación. Banco de Crédito del Perú. Redescubramos Lima. Iglesia de San Pedro. Lima: Banco de Crédito del Perú, pp. 45-56.

Wuffarden, L. (2019). La pintura y los programas iconográficos. En Ramón Mujica, Luis Wuffarden y Juan Dejo (Coords.). San Pedro de Lima. Iglesia del Antiguo Colegio Máximo de San Pablo. Lima: Banco de Crédito del Perú, pp. 205-267.

Recibido el 22 de junio de 2020 Aceptado el 19 de agosto de 2020 